\title{
Determining Price Reasonableness in Federal ESPCs
}

\author{
John A. Shonder and Erica Atkin
}

January 2005

Prepared by

OAK RIDGE NATIONAL LABORATORY

P.O. Box 2008, Oak Ridge, Tennessee 37831-6285,

managed by UT-Battelle, LLC

for the

U.S. DEPARTMENT OF ENERGY under contract DE-AC05-00OR22725 


\section{Contents}

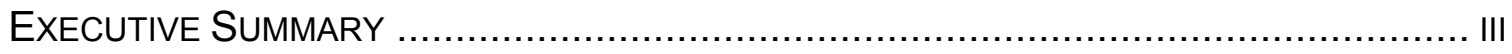

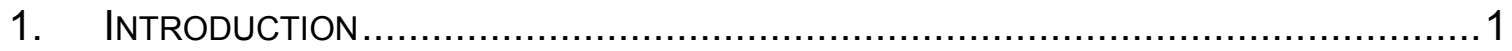

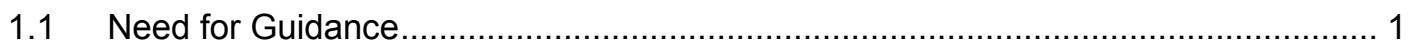

1.2 Importance of Price Reasonableness in ESPCs …............................................. 2

1.3 Price Reasonableness Working Group ............................................................... 3

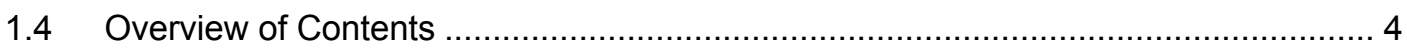

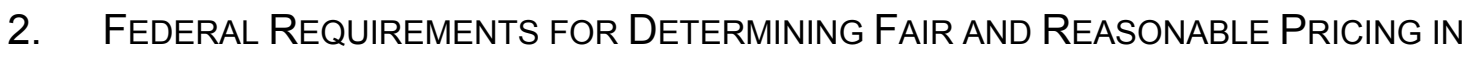

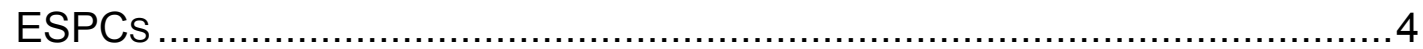

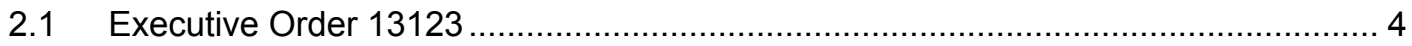

2.2 National Energy Conservation Policy Act and DOE Final Rule ............................... 5

2.3 FAR 15.404

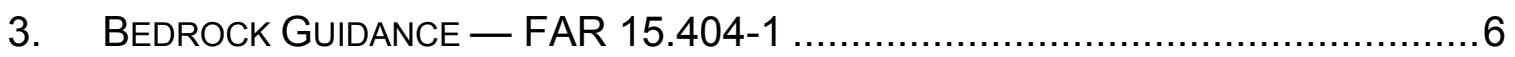

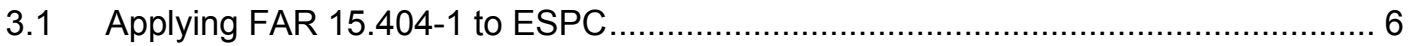

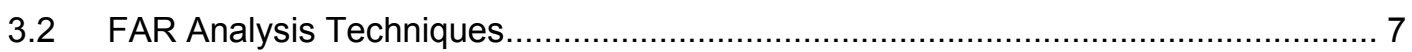

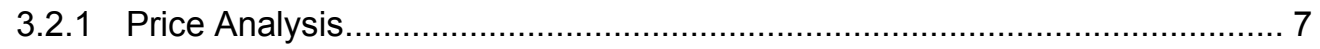

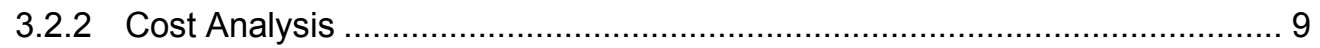

3.2.3 Technical Analysis ........................................................................ 10

3.2.4 Summary of Applicable FAR Proposal Analysis Techniques ..................... 11

4. Recommended Strategies for Cost-Effective Assurance of FAIR AND

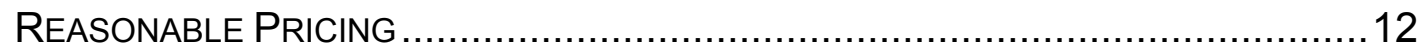

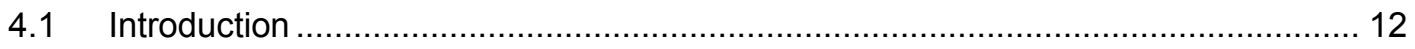

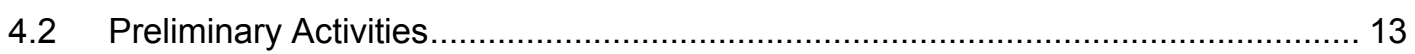

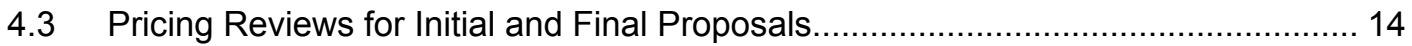

4.3.1 Appropriate Level of Review — Initial Proposal.......................................... 14

4.3.2 Appropriate Level of Review — Final Proposal ....................................... 16

4.3.3 ECM Pricing ..................................................................................... 16

4.3.4 Performance-Period-Services Prices........................................................... 20

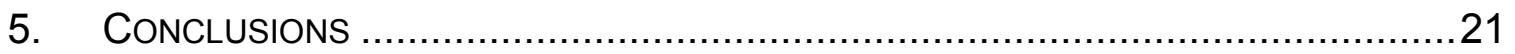

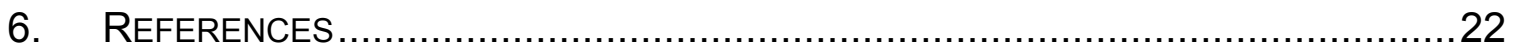

Appendix A - Charter for Price Reasonableness Working Group ............23

Appendix B - Membership of Price Reasonableness Working group ..........25

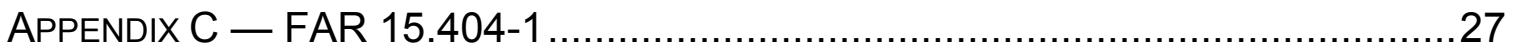

Appendix D - Benchmarks: A More Rigorous Approach to Price Analysis.. 33 


\section{EXECUTIVE SUMMARY}

This document reports the findings and implementation recommendations of the Price Reasonableness Working Group to the Federal ESPC Steering Committee. The working group was formed to address concerns of agencies and oversight organizations related to pricing and fair and reasonable price determination in federal energy savings performance contracts (ESPCs). This report comprises the working group's recommendations and is the proposed draft of a training curriculum on fair and reasonable price determination for users of federal ESPCs. The report includes

- A review of federal regulations applicable to determining price reasonableness of federal ESPCs (section 2),

- Brief descriptions of the techniques described in Federal Acquisition Regulations (FAR) 15.404-1 and their applicability to ESPCs (section 3), and

- Recommended strategies and procedures for cost-effectively completing price reasonableness determinations (sections 4).

Agencies have struggled with fair and reasonable price determinations in their ESPCs primarily because this alternative financing vehicle is relatively new and relatively rare in the federal sector. The methods of determining price reasonableness most familiar to federal contracting officers (price competition based on the government's design and specifications, in particular) are generally not applicable to ESPCs.

The regulatory requirements for determining price reasonableness in federal ESPCs have also been misunderstood, as federal procurement professionals who are inexperienced with ESPCs are further confused by multiple directives, including Executive Order 13123, which stresses life-cycle cost-effectiveness.

Uncertainty about applicable regulations and inconsistent practice and documentation among agencies have fueled claims that price reasonableness determinations have not been sufficiently rigorous in federal ESPCs or that the prices paid in ESPCs are generally higher than the prices paid for similar goods and services obtained through conventional procurements. While claims of excessive prices are largely unsubstantiated and based on anecdotal evidence, the perception that there is a problem is shared by many in the ESPC community and has been noted by auditors and oversight organizations.

The Price Reasonableness Working Group determined that a more formal emphasis on FAR 15.404-1 in the ESPC process could remove much of the doubt about price reasonableness determinations. The working group's recommended consensus policy on price reasonableness stresses the price analysis techniques described in the FAR that are applicable to ESPCs and includes guidance for agencies' use of these techniques in determining price reasonableness for their ESPC delivery orders.

The recommended policy and guidance, if communicated to federal ESPC stakeholders, can ensure that agencies will comply with the FAR in awarding ESPCs, obtain fair and reasonable prices and best value for the government, and follow procedures that provide auditable documentation of due diligence in price reasonableness determinations. 


\section{Determining Price Reasonableness in Federal ESPCs}

\section{INTRODUCTION}

This document reports the findings and implementation recommendations of the Price Reasonableness Working Group to the Federal ESPC Steering Committee. The working group was formed to address concerns of agencies and oversight organizations related to pricing and fair and reasonable price determination in federal energy savings performance contracts (ESPCs).

\section{$1.1 \quad$ Need for Guidance}

Agencies have struggled with fair and reasonable price determinations in their ESPCs primarily because this alternative financing vehicle is relatively new and relatively rare in the federal sector. All branches of the government have experience in implementing appropriations-funded contracts, and there are a number of effective methods to assure price reasonableness in these contracts. Implementing an ESPC, however, is fundamentally different from the process used in more conventional contracting mechanisms.

In particular, the methods of determining price reasonableness most familiar to federal contracting officers are generally not applicable to ESPCs. Most federal ESPC projects are implemented as delivery orders under one of the Defense or Energy Department's indefinite-quantity, indefinite-delivery (IDIQ) ESPCs without a true price competition, so competition at the contractor selection stage cannot be used to guarantee price reasonableness. ESPC projects are similar to design-build contracts, except that the energy services company (ESCO) generally develops a firm-fixed-price proposal when the ESCO-developed design is only about 30\% complete. Lacking complete cost data, it is difficult for the government to perform traditional cost analyses or to develop an independent cost estimate to compare with the ESCO's proposal. Unable to rely on customary methods, some agencies have struggled with how to perform timely, costeffective price review of ESPC projects.

The regulatory requirements for determining price reasonableness in federal ESPCs have also been misunderstood, as federal procurement professionals who are inexperienced with ESPCs are further confused by multiple directives that appear to provide conflicting guidance. Executive Order 13123, which is often cited as the impetus for the Department of Energy (DOE) Federal Energy Management Program's (FEMP's) Super ESPC program, stresses life-cycle cost-effectiveness, but contrary to common interpretation, does not supercede or replace overarching requirements of the Federal Acquisition Regulation (FAR). The federal requirements for determining price reasonableness in ESPCs are reviewed in section 2. 
Uncertainty about applicable regulations and inconsistent practice and documentation among agencies have fueled claims that price reasonableness determinations have not been sufficiently rigorous in federal ESPCs or that the prices paid in ESPCs are generally higher than the prices paid for similar goods and services obtained through conventional procurements. ${ }^{1}$ While claims of excessive prices are largely unsubstantiated and based on anecdotal evidence, the perception that there is a problem is shared by many in the ESPC community and has been noted by auditors and oversight organizations.

\subsection{Importance of Price Reasonableness in ESPCs}

The responsibility to ensure that the government pays fair and reasonable prices for the goods and services it buys is critical in ESPCs, where the procurement is financed over time. Figure 1 shows the distribution of costs over the lifetime of the typical ESPC project awarded under DOE's Super ESPC program. Implementation price, which is the installed cost of the energy conservation measures, accounts for the largest share of the total, $42.8 \%$. Financing-related costs, including interest, account for another $38.1 \%$, and these depend directly on the prices of energy conservation measures (ECMs). As the figure shows, when the ECM prices in the average Super ESPC project are increased by $10 \%$, the total sum of payments over time increases by $25.5 \%$.

Performance-period services account for the third largest cost component of the average ESPC project, at about 19\% of the total over the life of the project. Ensuring that prices for these services are fair and reasonable is also important. While these costs are not financed, they have an indirect effect on financing costs: Reducing the amount of guaranteed cost savings available for paying debt service increases the term of the

\footnotetext{
${ }^{1}$ The perception that prices are higher in ESPCs than in appropriations-funded projects is understandable, because direct comparison could indicate that they are. However, direct comparisons of the prices of ESPCs and appropriations-funded energy conservation projects are invalid comparisons. Most agency-level appropriations-funded energy conservation programs are carried out in two stages: Funding is first provided for detailed surveys and studies of a broad range of competing projects at different facilities. Program managers then select the projects with the best economics and provide funds for design completion and equipment installation until the available appropriated funds are all allocated. Although the expense of the cost-benefit analyses for all the conservation measures that were not cost-effective or were not funded for other reasons is very real, it is not included in the price of the winning projects. In ESPCs, on the other hand, it is the ESCO that performs cost-benefit studies, eventually proposing the conservation measures that are the most economically viable, and all of the survey and study costs are included in the price of the project. Because the costs of feasibility studies and project development are included in ESPCs but excluded from the prices of these agency-funded projects, the conservation measures installed under ESPCs appear to be more expensive.

Another misperception is that ESPCs are always less cost-effective than appropriations-funded energy projects because private-sector financing is more expensive than what can be obtained by the U.S. Treasury. In fact, careful comparisons of the costs of projects implemented through ESPCs and appropriations-funded programs with the two-stage process described in the preceding paragraph show that ESPCs are in many cases the better value. Often appropriations-funded projects must wait literally years to be implemented, resulting in lost energy and cost savings and inflated prices, and these costs can quickly exceed the cost that interest payments add to the ESPC project (Hughes, Shonder, Sharp, and Madgett, 2003).
} 
contract. A $10 \%$ increase in the cost of performance-period services increases total costs over the term of the average Super ESPC by $5.5 \%$.

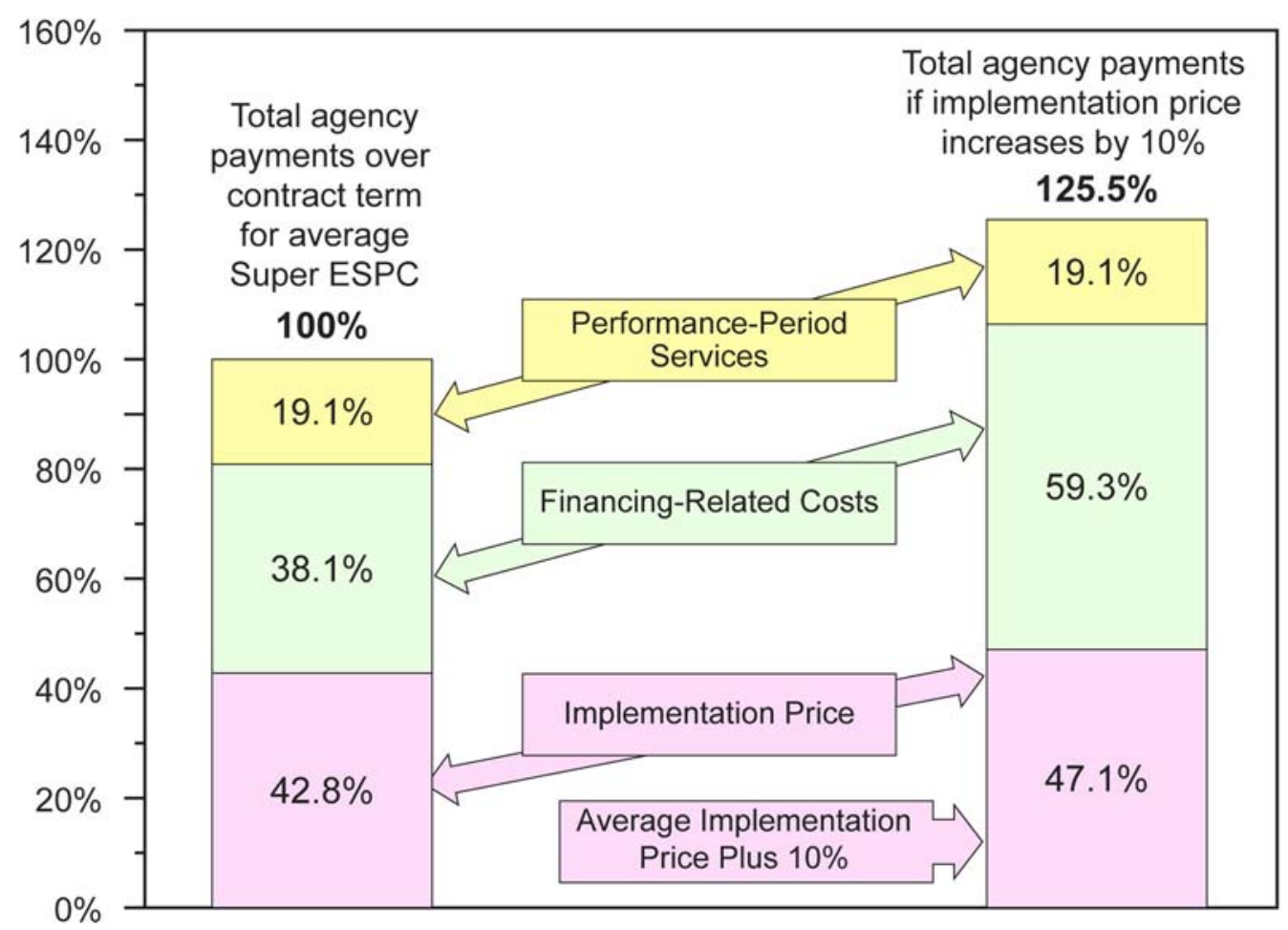

Figure 1. Assuring fair and reasonable pricing in ESPCs is perhaps more important in financed contracts such as ESPCs than in conventional contracts. If the implementation price for the average Super ESPC project increases by $10 \%$, total agency payments over the term of the contract increase by $25.5 \%$.

\subsection{Price Reasonableness Working Group}

The Federal ESPC Steering Committee authorized the formation of a Price Reasonableness Working Group to address this issue. The working group includes representatives of the four Armed Services, DOE, and the DOE National Laboratories. The objectives of the working group were to identify and document the approaches agencies have used for price review in ESPC projects, including best practices, and to develop consensus among the federal ESPC programs on implementation recommendations to users of federal ESPCs for performing price review in future projects.

The working group surveyed its members to determine how their organizations assure price reasonableness in ESPC contracts and found that all members were relying on their own interpretation of FAR 15.404-1, Proposal Analysis Techniques. Although FAR 15.404-1 was intended to apply to conventional multiple-bid, appropriations-funded 
contracts, many of the techniques it specifies are also useful for assuring price reasonableness in ESPCs. For this reason, the working group decided that a more formal emphasis on FAR 15.404-1 in the ESPC process could remove much of the doubt about price reasonableness determinations. Therefore, FAR 15.404-1 forms the basis for the working group's recommended consensus policy on price reasonableness.

\subsection{Overview of Contents}

The remainder of this report comprises the working group's implementation recommendations and is the proposed draft of a training curriculum on fair and reasonable price determination for users of federal ESPCs. The report includes

- A review of federal regulations applicable to determining price reasonableness of federal ESPCs (section 2),

- Brief descriptions of the techniques described in FAR 15.404-1 and their applicability to ESPCs (section 3), and

- $\quad$ Recommended strategies and procedures for cost-effectively completing price reasonableness determinations (section 4).

\section{Federal ReQuirements for Determining Fair ANd ReAsonable PRICING IN ESPCS}

The requirements for determining fair and reasonable pricing in federally awarded ESPCs are found in Executive Order 13123, the legislation that authorized federal ESPCs, and the federal regulations that implement the ESPC authority. ESPCs, like all government contracts, must comply with the FAR's solicitation and competition requirements.

\subsection{Executive Order 13123}

E.O. 13123, which is often cited as the impetus for FEMP's Super ESPC program, directs agencies to consider life-cycle cost in their deliberations about resource-efficiency investments, which includes ESPCs:

\footnotetext{
PART 4 - PROMOTING FEDERAL LEADERSHIP IN ENERGY

MANAGEMENT, Sec. 401. Life-Cycle Cost Analysis. Agencies shall use lifecycle cost analysis in making decisions about their investments in products, services, construction, and other projects to lower the Federal Government's costs and to reduce energy and water consumption. Where appropriate, agencies shall consider the life-cycle costs of combinations of projects, particularly to encourage bundling of energy efficiency projects with renewable energy projects. Agencies shall also retire inefficient equipment on an accelerated basis where replacement results in lower life-cycle costs. Agencies that minimize life-cycle costs with efficiency measures will be recognized in their scorecard evaluations.
}

The emphasis on life-cycle cost-effectiveness seems to have led to the perception in some quarters that price reasonableness is less important, as long as the project pays from 
savings. The perception is partially correct in that the reason life-cycle cost is emphasized is to allow consideration of advanced energy conservation measures that could potentially cost more - but have higher energy and energy cost savings - than more conventional conservations measures. However, the requirement to consider life-cycle cost does not replace or supercede the requirement to comply with the FAR and to perform fair and reasonable price determinations with due diligence. The intent is that the prices paid for the advanced ECMs - and for all equipment installed under ESPC - should be fair and reasonable, and in accordance with prices paid for similar equipment in the private sector.

\subsection{National Energy Conservation Policy Act and DOE Final Rule}

The National Energy Conservation Policy Act, as modified by the Energy Policy Act of 1992, established the authority for the government to enter into the guaranteed savings style of ESPCs. Title VIII, Section 801, directed the Secretary of Energy to "establish appropriate procedures and methods for use by Federal agencies to select, monitor, and terminate contracts with energy service contractors in accordance with laws governing Federal procurement that will achieve the intent of this section in a cost-effective manner," and in doing so, to "determine which existing regulations are inconsistent with the intent of this section and ... formulate substitute regulations consistent with laws governing Federal procurement."

DOE subsequently determined that requiring ESCOs to submit certified cost data is inconsistent with the intent of Section 801 of the Act. Specifically, the Final Rule on Energy Savings Performance Contracts, 10 CFR 436, section 33, paragraph (c) (2), reads:

Pursuant to the authority provided under section 304A(b)(1)(B) of the Federal Property and Administrative Services Act of 1049, the heads of procuring activities shall waive the requirement for submission of certified cost or pricing data. However, this does not exempt offerors from submitting information (including pricing information) required by the Federal agency to ensure the impartial and comprehensive evaluation of proposals.

The supplementary information provided with 10 CFR 436 emphasizes this point:

It should be noted, however, that the waiver of the requirement for certified cost or pricing is not intended to preclude contracting officers from requesting information considered necessary to determine whether a contractor's prices are fair and reasonable.

To summarize, 10 CFR 436.33 provides some guidance on price reasonableness in sections (c) (1) and (2). The final rule:

- Waived the requirement for certified pricing,

- Stated that offerors must nevertheless provide information requested by federal agencies, and

- Did not specify how agencies are to assure price reasonableness.

The fact that ESPCs include finance charges has led to further uncertainty. However, the working group believes that ESPCs must be approached in the same way an individual approaches the purchase of a home or an automobile — by first seeking a fair price for 
the item, and then seeking the best available financing. Seeking a fair price is the objective of a price reasonableness determination and is the focus of the remainder of this document.

\section{$2.3 \quad$ FAR 15.404}

ESPCs must comply with the FAR's solicitation and competition requirements, but if the FAR conflicts with EPACT or the DOE Final Rule, the latter take precedence over the FAR. There is no conflict in these regulations pertaining to price reasonableness determination. ESPC delivery orders, as government procurements, are required to comply with FAR Subpart 15.4 - Contract Pricing.

\section{BEDROCK GUIDANCE - FAR 15.404-1}

\subsection{Applying FAR 15.404-1 to ESPC}

ESPC delivery orders, as government procurements, are required to comply with FAR Subpart 15.4, "Contract Pricing." Price reasonableness determinations are required for all ESPC price components, including ECMs, performance-period services, and financing. (The Financing Cost Reduction Working Group's recommendations to the Federal ESPC Steering Committee, which cover price reasonableness determination for financing costs, are reported in Reducing Financing Costs for Federal ESPCs, available at www.ornl.gov/sci/femp/wg_financing.shtml.)

The FAR instructs contracting officers to purchase supplies and services from responsible sources at fair and reasonable prices. Although the FAR does not define what constitutes a fair and reasonable price, the term is understood to mean the price that would be paid by a prudent person considering the current market environment.

FAR 15.404-1, "Proposal Analysis Techniques," describes the techniques contracting officers are to use to ensure that final agreed-to prices are fair and reasonable. (FAR 15.404-1 is given in Appendix C.) The main techniques are

- price analysis,

- cost analysis, and

- technical analysis.

These techniques, discussed in section 3.2, can be used singly or in combination.

The FAR instructs contracting officers to require offerors to submit the smallest amount of information necessary to determine price reasonableness. This tends to favor price analysis. Where price reasonableness cannot be established through price analysis alone, cost analysis may be performed. This is a more detailed assessment of the need for and reasonableness of each of the individual cost elements that make up the offeror's price proposal, including labor, materials, and overheads, and tends to be more costly and timeconsuming than price analysis. Although this technique provides a more detailed analysis 
of a proposal, the final price reasonableness determination should be made on the basis of overall price.

Review by technical experts and individuals familiar with the equipment and services being procured is another valuable technique for establishing price reasonableness.

\subsection{FAR Analysis Techniques}

\subsubsection{Price Analysis}

Price analysis is defined as "the process of examining and evaluating a proposed price without evaluating its separate cost elements and proposed profit." This encompasses a number of different techniques. Many of these are directly applicable to ESPC, although not all are. The techniques described in the FAR are the following.

\subsubsection{Price competition}

The FAR considers the market forces inherent in the competitive bidding process to be adequate to establish price reasonableness, and the FAR lists price competition [FAR 15.404-1 (b)(2)(i)] as the preferred method of price analysis in traditional government contracting. Because in ESPCs the ESCO is selected before the project is defined sufficiently to support a true price competition, ESCO selection through price competition and hence use of competition for establishing price reasonableness is rarely used in ESPC. Agencies can, however, obtain competitive pricing by requiring ESCOs to solicit competitive bids from subcontractors.

\subsubsection{Comparison with previously proposed prices}

Comparison of previously proposed prices and previous Government and commercial contract prices with current proposed prices for the same or similar items, if both the validity of the comparison and the reasonableness of the previous price(s) can be established. - FAR 15.404-1 (b)(2)(ii)

For the most part, the equipment installed and the services provided under ESPC involve systems that provide electrical service, lighting, heating, air conditioning, and ventilation for buildings. Similar ECMs have usually been installed in the past at the same installation or at other installations, either in previously awarded ESPCs or in appropriations-funded energy conservation programs. Prices paid in the past can be used to determine whether the prices offered for similar equipment and services are fair and reasonable.

The project team often has access to a great deal of information on past pricing for similar ECMs from its own site or from agency-level service organizations. FEMP maintains a database of prices for all of the ECMs installed under its Super ESPCs and makes the information available as requested to project teams installing similar ECMs in other projects.

For comparisons to be valid, adjustments in the data are usually required. No two construction projects are identical — prices are affected by site-specific factors such as 
safety and security requirements and the cost of labor in the local economy. Likewise, no two contracting mechanisms are identical. Caution should be exercised when comparing prices offered in ESPCs, which are design-build contracts, to prices received for previous projects in which the site may have received funding for partial design from an agency energy conservation program. Adjustments for general inflation must be made as well.

\subsubsection{Parametric estimating methods}

Use of parametric estimating methods/application of rough yardsticks (such as dollars per pound or per horsepower, or other units) to highlight significant inconsistencies that warrant additional pricing inquiry. — FAR 15.404-1 (b)(2)(iii)

Other terms for such yardsticks are cost estimating relationship (CER) and price benchmarks. CERs and benchmarks are mathematical relationships, usually based on statistical analysis, between price as the dependent variable and one or more physical characteristics of the item or system purchased as independent variables. CERs can be used to extend the technique of comparing proposed prices with previously proposed prices described above.

As a simple example, suppose a site wishes to replace a 500-ton centrifugal chiller. The site recently paid $\$ 162,000$ to replace a 200 -ton centrifugal chiller and $\$ 366,000$ to replace an 800-ton chiller, but because there is no recent pricing information available for replacement of 500-ton chillers, strict reliance on past pricing would not provide enough information to establish price reasonableness. A simple price benchmark would be to assume a straight-line relationship between installed price and equipment size. Based on the two previous chiller replacements, the benchmark relationship is Price $=\$ 94,000+$ $340 \times$ tons, so a reasonable price for replacement of a 500 -ton chiller would be $\$ 94,000+$ $340 \times 500=\$ 264,000$.

Most benchmarks or CERs are based on much more data than this and require corrections for project scope, general price inflation, and geographical location, as well as statistical analysis to determine the relationship itself. However, information on past pricing from the site, the agency, or other sources can be used by acquisition teams to develop their own CERs.

FEMP has developed CERs for some of the more commonly installed ECMs based on data from past Super ESPC projects and appropriations-funded projects and makes this information available to project teams.

\subsubsection{Comparison with published prices}

Comparison with competitive published price lists, published market prices of commodities, similar indexes, and discount or rebate arrangements.

$$
\text { - FAR 15.404-1 (b)(2)(iv) }
$$

This refers to catalog prices and GSA schedules, as well as cost-estimating guides published by firms such as R. S. Means, Marshall and Swift, and Craftsman. These lists and guides provide pricing for specific commercial items such as boilers and chillers. ESPC projects often involve demolition of existing equipment as well as installation of 
new equipment, and so the ECM price will include more than just the commercial cost.

For this reason, price lists and guides find more use in cost analysis than in price analysis.

\subsubsection{Market research}

Comparison of proposed prices with prices obtained through market research for the same or similar items. - FAR 15.404-1 (b)(2)(vi)

In some cases useful pricing information can be obtained through market research. An example would be the solicitation of price quotes from other suppliers. However, as with the use of price lists and guides, the information obtained usually applies to specific commercial items. Again, because ESPC projects often involve demolition and construction, information obtained through market research tends to be more useful in cost analysis than in price analysis.

\subsubsection{Analysis of pricing information provided by the offeror}

Prices proposed by the offeror to other customers can also be used to establish price reasonableness [FAR 15.404-1 (b)(2)(vii)], although 15.402 (a)(2)(i) lists the preferred source of information to be that which is available within the government, followed by that which is available from sources other than the offeror. Information provided by the offeror is only to be used if necessary.

\subsubsection{Comparison of proposed prices with independent Government cost estimates}

While usually associated with more traditional contracting methods, an independent government estimate (IGE) can also be used to establish price reasonableness in ESPCs if the necessary resources are available to develop one [FAR 15.404-1 (b)(2)(v)]. The IGE is the government's estimate of the resources needed and the estimated cost of those resources that a prudent contractor would incur in the performance of a contract. The estimate includes both direct costs (e.g., labor, supplies, equipment, and transportation) and indirect costs (e.g., labor burden, overhead, general and administrative expense, and profit or fee). Development of an IGE typically requires designs to be at the $95 \%$ stage. This limits their usefulness in ESPC programs where contracts are signed at the $30 \%$ design stage, but some programs do postpone ESPC project award until $95 \%$ designs are available.

\subsubsection{Cost Analysis}

If price reasonableness cannot be established by the price analysis techniques described above, contracting officers may use cost analysis, defined in FAR §15.404-1(c)(1) as

"the review and evaluation of the separate cost elements and profit in an offeror's or contractor's proposal (including cost or pricing data or information other than cost or pricing data), and the application of judgment to determine how well the proposed costs represent what the cost of the contract should be, assuming reasonable economy and efficiency." 
For a cost analysis, the contracting officer needs a detailed breakdown of the offeror's price into material, labor, and overhead costs. While several different cost analysis techniques are listed in FAR 15.404-1 (c), the process basically comes down to verifying the necessity for and reasonableness of each of the elements in the offeror's cost proposal. Many price analysis techniques are applicable in cost analysis as well to assess the reasonableness of individual cost elements. For example, proposed costs of individual pieces of capital equipment can be compared with previously proposed prices for similarly sized equipment. Price benchmarks can also be used at the level of individual costs. Price lists, catalogs, and cost estimating guides are generally most useful in cost analysis.

It should be noted that the more detailed, in-depth review carried out in a cost analysis does not necessarily assure price reasonableness. For example, consider the procurement of a computer. An offeror could submit a detailed price proposal including all of the materials and labor required to fabricate each individual electronic component and combine them together on circuit boards. While cost analysis might judge each individual cost to be fair and reasonable, the overall price of building a computer from scratch would be much higher than purchasing one on the open market. For this reason, the FAR specifies that even where cost analysis is used, price analysis should also be used to verify that the overall price is fair and reasonable.

\subsubsection{Technical Analysis}

In technical analysis, the contracting officer seeks the opinion of individuals with specialized knowledge of the equipment or services being procured [FAR 15.404-1 (e)]. These individuals would generally be professional cost estimators who would examine, at a minimum, the types and quantities of materials proposed and the need for the types and quantities of labor hours and the labor mix. Also, agency or site-level engineering staff are usually integral members of the ESPC project team, and their analysis of cost proposals is carried out as a normal part of the review process. Less common ECMs such as geothermal heat pumps or combined heat and power equipment may require review by independent experts such as DOE National Laboratory personnel. 


\subsubsection{Summary of Applicable FAR Proposal Analysis Techniques}

The recommended techniques and their application to federal ESPCs are summarized below.

\begin{tabular}{|c|c|}
\hline FAR Technique & Application to Federal ESPCs \\
\hline $\begin{array}{l}\text { 1. Price analysis - Analyze price of each } \\
\text { ECM, each performance-period service, and } \\
\text { financing individually. }\end{array}$ & $\begin{array}{l}\text { Is preferred over and requires less information } \\
\text { than cost analysis }\end{array}$ \\
\hline a. Price competition & $\begin{array}{l}\text { First preference, but not generally done in } \\
\text { ESPCs. ESCO could compete subcontracts } \\
\text { and document results. }\end{array}$ \\
\hline $\begin{array}{l}\text { b. Comparison with previously proposed } \\
\text { prices and previous government and } \\
\text { commercial contract prices }\end{array}$ & Can be applicable if data is available. \\
\hline $\begin{array}{l}\text { c. Parametric estimating methods }- \text { An } \\
\text { extension of comparing proposed and } \\
\text { past prices - cost estimating } \\
\text { relationships (e.g., dollars per ton of } \\
\text { chiller capacity) calculated from past } \\
\text { pricing data }\end{array}$ & $\begin{array}{l}\text { Use FEMP Benchmarking Tool, ECM Locator, } \\
\text { site- and/or agency-level info on past pricing }\end{array}$ \\
\hline d. Comparison with published prices & More applicable to cost analysis. \\
\hline e. Market research & More applicable to cost analysis. \\
\hline $\begin{array}{l}\text { f. Analysis of pricing information provided by } \\
\text { offeror }\end{array}$ & $\begin{array}{l}\text { Using information from within government is } \\
\text { preferable to using information from offeror. }\end{array}$ \\
\hline $\begin{array}{l}\text { g. Comparison of proposed prices with } \\
\text { independent government cost estimates }\end{array}$ & $\begin{array}{l}\text { Can be used in ESPC, but cost estimators } \\
\text { require near-complete designs. }\end{array}$ \\
\hline $\begin{array}{l}\text { 2. Cost analysis - Analyze price of each } \\
\text { ECM, each performance-period service, and } \\
\text { financing individually }\end{array}$ & $\begin{array}{l}\text { More costly and time-consuming than price } \\
\text { analysis. Price analysis still needed for final } \\
\text { reasonableness determination. }\end{array}$ \\
\hline $\begin{array}{l}\text { 3. Technical analysis - Consultation with } \\
\text { individuals with specialized knowledge of } \\
\text { equipment or services being procured, who } \\
\text { examine, at minimum, types and quantities of } \\
\text { materials and labor requirements and costs }\end{array}$ & $\begin{array}{l}\text { Depending on the type of expertise needed, } \\
\text { could be provided by site or agency } \\
\text { engineering staff, independent experts (e.g., } \\
\text { DOE National Labs), or others, but would } \\
\text { generally be professional cost estimators. }\end{array}$ \\
\hline
\end{tabular}




\section{Recommended Strategies for Cost-Effective Assurance of FAIR AND REASONABLE PRICING}

\subsection{Introduction}

The recommended process for determining price reasonableness in federal ESPCs complies with the FAR's guidance on proposal analysis and relies on the techniques described in FAR 15.404-1. Undoubtedly, many of these activities are already being carried out by agencies in some form, but until now they have not been formally spelled out.

The key elements of FAR guidance that apply to federal ESPCs are as follows:

- Price reasonableness determinations are required for all ESPC price components, including ECMs, performance-period services, and financing costs. Pricing of each ECM and each service should be considered individually.

- Contracting officers are directed to require offerors to submit the smallest amount of information necessary to determine price reasonableness. This tends to favor price analysis over cost analysis.

- Where price reasonableness cannot be established through price analysis alone, cost analysis may be used.

- Even when cost analysis is used, price analysis should also be used to verify that the overall price is fair and reasonable.

- The main techniques recommended for price reasonableness determination that are applicable to federal ESPCs, in order of preference, are the following:

- Price analysis

- Comparison with previously proposed prices

- Parametric estimating methods

- Technical analysis

- Cost analysis

There are several ESPC vehicles available to agencies, and the implementation process is slightly different for each one, but all follow the same basic outline. In the following sections we use DOE's Super ESPC as an example, but these recommendations are generally applicable to any of the federal IDIQ ESPCs.

Activities related to price reasonableness determination fall into three areas and correspond roughly to Phases 1,2, and 3 of the process of developing an ESPC delivery order, respectively:

- Preliminary activities - Phase 1: Project planning

- Review of initial proposal - Phase 2: Initial project development

- Review of final proposal - Phase 3: Negotiation and award of final delivery order 


\subsection{Preliminary Activities}

The project planning phase encompasses initial exploration of the feasibility of a payfrom-savings project and preliminary communications between the site and one or more ESCOs. The agency acquisition team, which guides the project to its completion, is formed at this time. The acquisition team should establish early on that one of its key objectives is to obtain fair and reasonable prices for the equipment and services that are being contracted for.

The two key members of the acquisition team are the Contracting Officer (CO) and the Site Technical Representative (STR). It is the CO's responsibility to make the team aware that the prices for ECMs and performance-period services received in the ESPC must be fair and reasonable according to the FAR. Because the focus in developing ESPCs is often on the requirement for the project to pay for itself out of the savings it generates, this concept may be unclear to some individuals, so it is worth emphasizing. Discussions with ESCOs should make this clear as well.

Although nothing is finalized at this stage, sites usually begin with some specific ECMs in mind, and the team should begin to consider how price reasonableness determinations will be performed for each one. Some questions to consider are:

- Are there any available price benchmarks or cost estimating relationships for these ECMs?

- Have similar ECMs been installed at this site in the past?

- If so, who at the site is familiar with the work?

- Can the total installation price (including feasibility/initial design) of these previously installed ECMs be established?

- Are there conditions/regulations at the site that could make these ECMs more expensive (or less expensive) to install than at other sites?

- What type of information can the project facilitator provide?

- Is there a need for assistance from outside sources (agency support organizations, DOE, private subcontractors)?

- Who are some likely candidates to provide the information required?

- What is the cost of using these sources?

- What kind of lead time is involved in obtaining them?

- What other information sources are available to make the price reasonableness determination?

- Are there any agency-specific policies on price reasonableness that must be followed?

In addition to ECM prices, the acquisition team must ensure that fair and reasonable prices are received for performance-period services such as operations and maintenance $(\mathrm{O} \& \mathrm{M})$, repair and replacement (R\&R), and measurement and verification (M\&V) of savings. The team should begin considering how the price reasonableness determinations will be made for these services. Some questions to consider include the following: 
- Who will be performing O\&M and R\&R on the installed equipment - the ESCO or the site?

- If similar ECMs have been installed at the site in the past, is there information available on their O\&M costs?

- What M\&V options and methods are typically used for ECMs like these?

- What cost information is available for these $\mathrm{M} \& \mathrm{~V}$ activities?

- What type of information can the project facilitator provide?

- Is there a need for assistance from outside sources?

- Who are some likely candidates to provide the information required?

- What is the cost of using these sources?

- What kind of lead time is needed in order to obtain them?

- What other information sources are available?

In the project planning stage, the main concern is to put these questions on the table so that the acquisition team recognizes the importance of price reasonableness and can begin considering how to address it.

\subsection{Pricing Reviews for Initial and Final Proposals}

The recommended process for reviewing pricing is basically the same for both initial and final proposals, as charted in Figure 2. However, the goals of the two reviews and expected levels of effort for each are very different.

Review of pricing in the initial proposal is a quick once-through to ensure that the proposed prices are realistic, as part of the effort to determine whether the proposed project is feasible and adequately addresses the agency's needs and priorities.

The final proposal requires more intensive price review. The final proposal contains the financial schedules that define the deal the agency will live with for the duration of the ESPC term and is the true object of the FAR's requirements for contracting officers to establish that prices in government contracts are fair and reasonable.

\subsubsection{Appropriate Level of Review - Initial Proposal}

The initial proposal is intended to give the agency enough information to make a confident decision on whether to proceed with the project, but is not expected to reflect a complete understanding of agency- and site-specific requirements. The initial proposal is a vehicle for establishing the viability of an ESPC project at the facility, for reaching general agreement on the scope of a feasible project, and for making the go or no-go decision. 


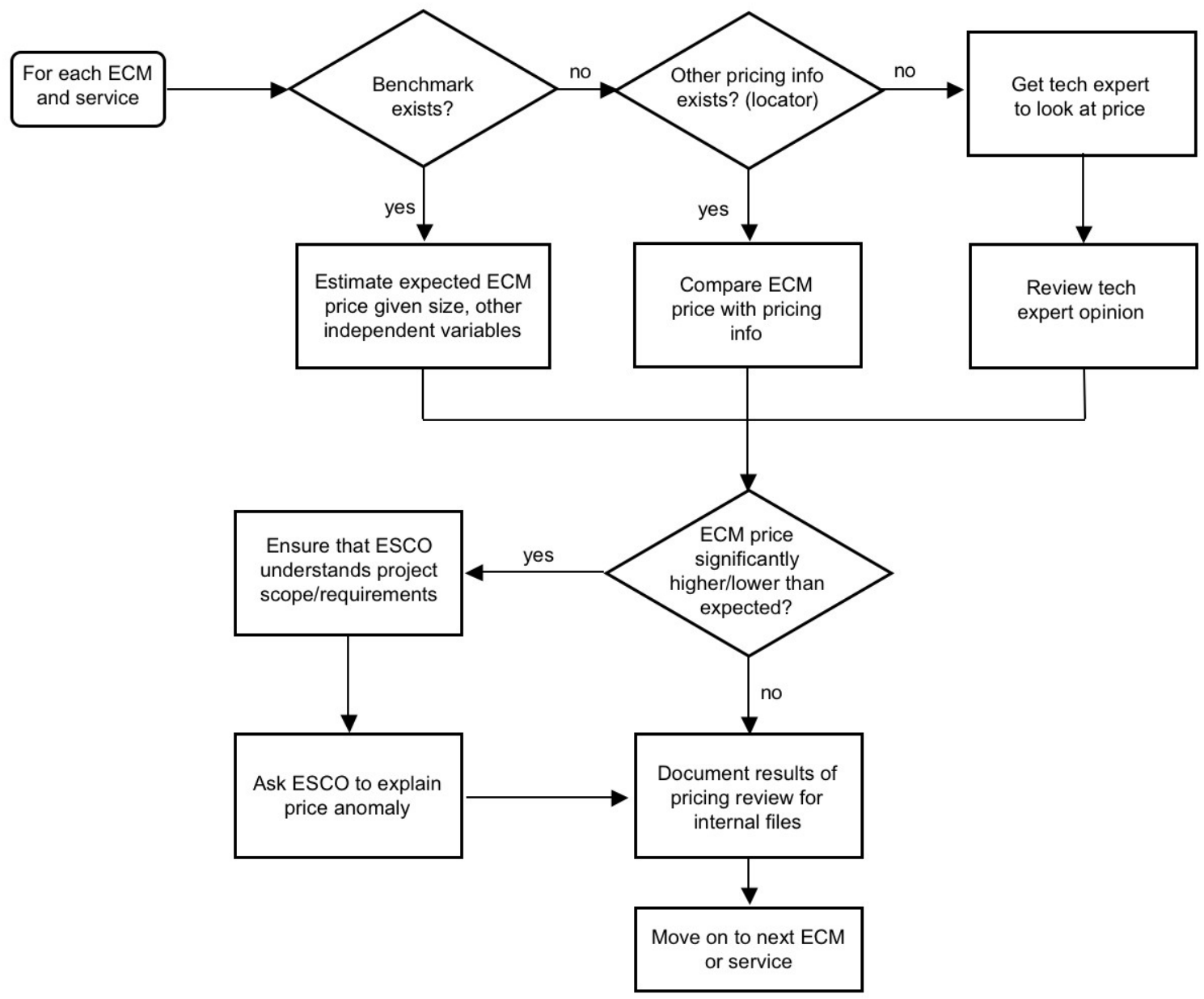

Figure 2. Flow chart showing the process recommended for the acquisition team to use in reviewing pricing of the initial and final proposals.

The initial proposal includes general ECM descriptions and preliminary estimates of prices and savings based on assumptions and engineering calculations, but no system design or engineering will have been done, and no subcontractors' quotes will have been obtained. Prices in the initial proposal are estimates based on the ESCO's own benchmarks, cost estimating relationships, and prices the ESCO and its subcontractors have charged for previous work. Review of pricing in the initial proposal should be commensurate with the preliminary nature of those price estimates and should correspond to the overall goal at this stage of reaching general agreements about the scope and shape of the project.

Price review that seeks a level of precision greater than that in the estimated prices in the initial proposal is not needed and is not cost-effective. However, the agency must ensure that preliminary prices are realistic in order to shape the scope of the project to meet the government's needs as completely as possible. If pricing is unrealistically high, ECMs that the agency needs may not appear to be feasible. If pricing is unrealistically low, the agency may be disappointed later to find that high-priority ECMs must be dropped to make the project pay from savings. 
After completing review of pricing in the initial proposal, the acquisition team should submit written comments to the ESCO (concerning both technical review and pricing review) and require written replies. The written documentation can help avoid misunderstandings and provides backup for auditors and others who may be interested in the development of the project.

\subsubsection{Appropriate Level of Review - Final Proposal}

The final proposal is the precursor of a contract that obligates the government to make payments over a period of years, so it is critical to ensure that the prices proposed for ECMs and performance-period services are fair and reasonable. When the final proposal is submitted, engineering designs will be about $30 \%$ complete, and the proposal should include backup information supporting the proposed pricing. The acquisition team will be able to use this information in addition to pricing benchmarks and other comparative prices to evaluate price reasonableness.

If any of the checks raise questions about the proposed pricing, the questions should be put to the ESCO and resolved during final contract negotiations. All information generated during the price reasonableness determination should be placed in a file for reference.

\subsubsection{ECM Pricing}

\subsubsection{Competition}

Competition is the FAR's first preference for establishing price reasonableness. Although price competition is not applicable at the initial proposal stage and has not been widely used in federal ESPCs, it would be possible to require the ESCO to compete the subcontracted portions of the project. Subcontract competition could take place before the award of the delivery order. Alternatively, all ECM subcontracts, or just disputed ECMs, could be competed after award and the contract modified to accommodate price changes.

\subsubsection{Price Analysis - Comparison with previously proposed prices and benchmarks}

After competition, the preferred methods of determining price reasonableness are price analysis techniques that compare proposed prices with previously obtained prices for similar goods and services obtained by the government, along with parametric estimating methods using price benchmarks, cost-estimating relationships, or rules of thumb [FAR 15.404-1 (b)(2)(ii-iii)].

Parametric estimating methods are closely related to and sometimes overlapping with

price comparison techniques, and both are well suited for price review for initial and final ESPC proposals. Comparable information on previously proposed prices can come from several sources:

- The facility's data on its own past energy projects

- Data on past energy projects compiled by the agency

- FEMP's ECM Benchmarking Tool 
- FEMP's ECM Locator

Acquisition team members may be able to use price information from past energy projects at their own facility, or pricing or benchmarking information maintained at the agency level. If existing data can be normalized or adjusted to make valid comparisons possible, these are the most cost-effective ways to establish price reasonableness. The following discussions of FEMP's ECM Benchmarking and ECM Locator tools and an example of reviewing ECM prices from an initial proposal illustrate how this information is used to make valid price comparisons.

Appendix D describes how price benchmarks are derived from pricing data.

\section{ECM Benchmarking Tool}

FEMP's ECM Benchmarking Tool incorporates data from all the awarded Super ESPC projects, plus some appropriations-funded energy projects. Benchmarks are established for four ECMs that are common in Super ESPCs - lighting, chiller replacements, variable-frequency drives, and geothermal heat pumps. The data include ECM price (including markup), date, location, and size. The benchmarking tool converts past prices to current dollars and adjusts them for regional differences for comparison to proposed prices.

Although these benchmarks alone may not be able to definitively, precisely determine price reasonableness, they are a cost-effective way to check whether prices are "in the ballpark." The benchmarks can be used to focus effort by eliminating prices that appear to be reasonable from further scrutiny. The FEMP team can use the benchmarks to show where the proposed price for a particular ECM fits into the array of past prices for similar ECMs. If the price falls near the middle or in the middle-lower end of the price range, the agency may assume that the price is "in the ballpark." Reviewers can then move on to check other prices.

If the price is at either extreme, the agency should pursue more information, either through additional price analysis, by consulting with technical experts, or by obtaining more information from the ESCO.

\section{ECM Locator}

For ECMs other than lighting, variable-frequency drives, chiller replacements, and geothermal heat pumps, FEMP's ECM Locator can be used to compare previous and proposed prices. Data on all ECMs ever awarded under the Super ESPCs, plus some appropriations-funded projects, is accessible through ECM Locator. The tool contains pricing information on the selected ECM, allowing simple comparisons with the proposed ECM. There is no automatic adjustment of past ECM prices for data and location, and size variables are not as accurate in Locator as in the ECM Benchmarking Tool.

ECM Locator can be an effective means of finding additional information on ECMs of interest. The FEMP team can in some cases check the ECM descriptions in the final proposals from which the data came and adjust the prices for closer comparison. The 
ECM Locator can also provide leads to the facility or energy managers who implemented the ECM in question, who can often provide more detailed information.

\section{Example of Reviewing ECM Prices from Super ESPC Initial Proposal}

The following is an example of applying the recommended process in review of an initial proposal. ECM implementation prices are found in column (c) on schedule DO-2. Figure 3 is a DO-2 schedule from a hypothetical initial proposal with four ECMs. Note that ECMs 1, 2, and 3 include nominal sizing information. DOE requires this information to be included on the DO schedule to facilitate price reasonableness determination. ${ }^{2}$

\section{IMPLEMENTATION PRICE BY ECM}

\begin{tabular}{|c|c|c|}
\hline Project Site: & Delivery Order No: & Contractor Name: \\
\hline 0 & 0 & 0 \\
\hline
\end{tabular}

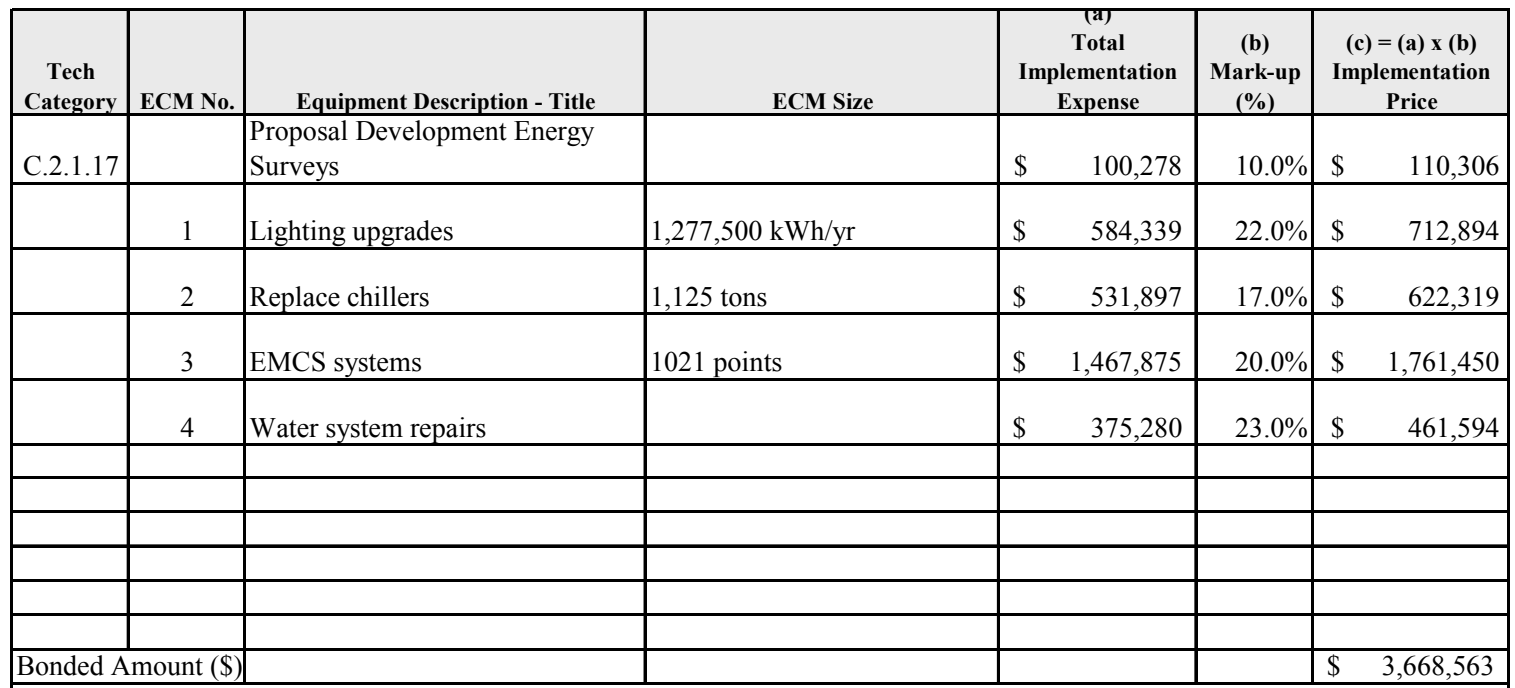

Notes:

1) Total Implementation Expenses shall include only direct costs, and no performance period expenses.

2) Contractor shall identify direct costs for DES and proposal development costs as a separate line item, as applicable.

3) Contractor shall attach adequate supporting information detailing total implementation expenses (direct costs), in accordance with Section H.24.2 of the contract.

4) Contractor shall propose bonded amount representıng the basis of establishıng performance and payment bonds per Section $\mathrm{H} .17$ of the contract, as required.

5) Attached supporting information shall be presented to identify portions of ECM or project expenses included in proposed bonded amount.

6) Proposed Bonded Amount is assumed to include markup applied to implementation expenses above, unless otherwise specified by Contractor. 7) For the following ECMs, enter the total installed capacity of new equipment in the units specified (e.g., chillers-150); chillers and packaged units in tons, VFDs in hp, boilers and furnaces in input Btu/hr, BAS/EMCS in number of points, transformers in kVA, generators in kW. For lighting ECMs, specify baseline $\mathrm{kW}$ treated.

Figure 3. DO-2 Schedule for an ESPC project with four ECMs.

\footnotetext{
${ }^{2}$ The accuracy and usefulness of benchmarks is directly related to the quantity of past pricing information available. Price benchmarks can only be developed for ECMs having similar technical scopes and for which a significant amount of data is available, which means that effective benchmarks can generally only be developed at the agency level. Obviously, FEMP's benchmarks presently do not cover all ECMs that will be implemented in federal ESPCs. The usefulness and applicability of these benchmarks (and ECM Locator) could be significantly improved by adding data from other agencies. Much data could be obtained with a very small investment of effort. For example, data on projects funded by the Department of Defense's Energy Conservation Investment Program would be easily accessible if size information were added to the cover sheets of the feasibility studies for the program's projects.
} 
For ECM No. 2, the acquisition team must determine if the proposed price is fair and reasonable for replacing 1125 tons of chiller capacity. First, to calculate the total proposed cost, a share of survey costs must be added to the implementation price. The DO-2 schedule breaks out "Proposal Development Energy Surveys" as a separate cost, as required by DOE, which makes it convenient to determine the percentage of the total these costs represent - about 3\% in this case. (The FEMP ESPC team can provide Super ESPC program averages of overall survey costs to help the project team decide whether the proposed costs are reasonable.) The cost of the energy surveys must be added in to determine the true ECM cost. Survey costs vary by ECM, but typically represent less than $5 \%$ of the total implementation price, and we recommend apportioning the survey costs to each ECM according to the percentage of the total that the ECM cost represents.

The total of the marked-up costs for the ECMs in Figure 3 is $\$ 3,558,257$ (\$3,668,563$\$ 110,306$ survey costs), and the marked-up cost of the chiller replacement ECM represents about $17.5 \%$ of this total $(\$ 622,319 / \$ 3,558,257)$. The total cost of the chiller replacement is then the marked-up price from column (c), plus $17.5 \%$ of the "Proposal Development Energy Surveys" cost. The total is $\$ 622,319+0.175 \times \$ 105,758=$ $\$ 640,827$. This is the cost that should be compared to the pricing benchmark to determine whether it is reasonable for the installation of 1125 tons of chiller capacity.

If a price benchmark formula or price estimating relationship is available for the ECM, the acquisition team should calculate the expected price given the ECM size listed in schedule DO-2, and compare that to the proposed price.

\section{Pricing from previous contracts}

Not all ECMs lend themselves to the development of pricing benchmarks or rules of thumb. However, contracting officers usually have access to pricing from previous contracts for installation or repair of similar equipment that can prove useful. For example, ECM No. 4 in Figure 3 is water system repairs. If repairs to the water system have been made in the past, the acquisition team can compare that pricing with the offered price of $\$ 461,494$ (plus the portion of the survey costs that apply to it). To determine whether the price is reasonable the team must consider the scope of the proposed project compared to the scope of past projects and normalize prices for regional cost differences and price inflation over time. This may require consultation with experts on the technology being proposed.

\subsubsection{Technical Analysis}

If valid price comparisons cannot be done or are inconclusive, the contracting officer may seek the opinions of individuals with specialized knowledge of the equipment or services being procured, or "technical experts." Technical experts here are understood to mean professional cost estimators or any technical specialists who support the acquisition team. In federal ESPCs, technical analysis might be provided by any of the following:

- Site-level engineering staff

- Agency-level experts (e.g., the Army Corps of Engineers, Naval Facilities Engineering Support Center, GSA's Energy Center of Expertise, etc.) 
- FEMP ESPC team members

- Independent experts with particular technologies (geothermal heat pumps, wind, solar, combined heat and power) from DOE National Laboratories or contractors

- Professional cost estimators

It will be most cost-effective for the technical specialists who are already supporting the acquisition team to review the information in the proposal and provide opinions on the reasonableness of the proposed costs as well as the technical merit of the design. These technical experts may use their own pricing benchmarks and rules of thumb to determine what is a fair price for a project of the requested size.

In some cases, the site may require a professional cost estimator to develop an independent estimate of project costs without reference to the cost information the ESCO provides. This requires the ESCO to develop a fairly complete design before the contract is awarded. The cost estimator should submit a written opinion as to whether the proposed ECM cost is fair and reasonable. The use of technical experts to perform cost analysis is a combination of FAR 15.404-1 paragraphs (e) and (c) (2) (i).

\subsubsection{Performance-Period-Services Prices}

Establishing that prices for performance-period services $(\mathrm{O} \& \mathrm{M}, \mathrm{R} \& \mathrm{R}, \mathrm{M} \& \mathrm{~V})$ are fair and reasonable is similar to determining price reasonableness for ECMs.

Responsibility for performance-period services is negotiable, and the proposal should reflect the site's decision as to who will perform these activities. (In Super ESPCs, assignments are shown in the Risk/Responsibility Matrix, which is part of the contract, and Schedule DO-3 contains proposed pricing for performance-period services.)

The proposal should include supporting information describing the activities to be carried out and the level of effort expected. Prices for performance-period services cover mainly labor hours. Preventive maintenance and R\&R prices also include replacement parts.

A primary standard for comparison will be the cost of previous O\&M and R\&R contracts at the site for similar equipment, or agency support organizations may be able to provide prices for similar contracts at other sites. Benchmark prices may also exists for some common maintenance activities.

Technical experts who review ECM designs may also need to review proposed O\&M and/or R\&R services to determine whether they are necessary and whether their pricing is reasonable for the level of effort proposed. The experts should provide written documentation of their opinions.

FEMP's data on Super ESPC projects does include average annual costs for O\&M, R\&R, and $\mathrm{M} \& \mathrm{~V}$ as a percentage of guaranteed savings, which may be useful as general rules of thumb.

$\mathrm{M} \& \mathrm{~V}$ is a requirement in federal ESPCs, but there is a wide range of options depending on the site's requirements, the particular ECM, and the perceived level of risk. Proposed 
prices for $\mathrm{M} \& \mathrm{~V}$ can be compared with the price of $\mathrm{M} \& \mathrm{~V}$ on similar ECMs at the same or other sites, if such information is available.

Performance-period services are a recurring cost throughout the life of the contract, and the proposals will include inflation factors that escalate the prices from year to year. These inflation factors should be no higher than the inflation rate published each April by NIST in the Annual Supplement to Handbook 135, "Energy Price Indices and Discount Factors for Life-Cycle Cost Analysis."

\section{Conclusions}

Making price reasonableness determinations in ESPCs has been problematic for a number of reasons. First, ESPCs represent a new way of doing business that is very different from the traditional government procurement process. In an ESPC, a single ESCO obtains financing to purchase and install equipment at a government site. In most cases the government pays nothing up front, but agrees to make regular payments to the ESCO out of the energy cost savings generated by the equipment. Long-term contracts are signed on the basis of firm-fixed-price proposals prepared at about the $30 \%$ design stage. In most cases there is no opportunity for price competition facilitated by multiple

bids, and insufficient design information is available for the development of independent government estimates, though some agencies have developed a process whereby $95 \%$ designs must be completed before contracts are awarded.

An ESPC is simply a procurement in which the government is purchasing equipment and services and paying for them over time out of the project's guaranteed savings to energy and related O\&M budgets. As in any government procurement, the FAR does apply, and FAR $§ 15.404-1$ provides a detailed description of the techniques to be used to ensure that the prices paid are fair and reasonable.

This document provides concrete recommendations for using the proposal analysis techniques of FAR 15.404-1 in ESPCs. A procedure is outlined for integrating price reasonableness considerations during review of the initial and final proposals. The procedure refers specifically to FEMP's Super ESPC process, but is generally applicable to all federal ESPCs.

The recommended policy and guidance, if communicated to federal ESPC stakeholders, can ensure that agencies will comply with the FAR in awarding ESPCs, obtain fair and reasonable prices and best value for the government, and follow procedures that provide auditable documentation of due diligence in price reasonableness determinations. 


\section{References}

Hughes, P. J., Shonder, J. A., Sharp, T., and Madgett, M. 2003. Evaluation of Federal Energy Savings Performance Contracting - Methodology for Comparing Processes and Costs of ESPC and Appropriations-Funded Energy Projects. Oak Ridge National Laboratory, ORNL/TM-2002/150.

R.S. Means. Mechanical Cost Data, $28^{\text {th }}$ Annual Edition: HVAC and Controls. Kingston, Mass., 2005.

R.S. Means. Facilities Maintenance \& Repair Cost Data. Kingston, Mass., 2005. 


\section{APPENDIX A - \\ Charter for Price Reasonableness Working Group}

\section{$\underline{\text { Background }}$}

In conventional bid-to-spec contracts implemented with appropriated funds, federal agencies receive construction bids from multiple competing offerors based on a completed design. In some cases the agency may develop its own independent cost estimate as well. The price competition between offerors and the independent government estimate provide assurance that the prices received are fair and reasonable. A major difference with energy savings performance contracts (ESPC) is that a single energy services company (ESCO) develops a firm-fixed-price bid based on a design that is only about $30 \%$ complete. Because of this difference, some agencies have struggled with how to perform timely, cost-effective price review of ESPC projects. There is a need to pool the experience of the various federal agencies, and to use that experience to develop consensus recommendations that agencies can use for price review in ESPC projects.

\section{$\underline{\text { Objectives }}$}

- Identify the approaches agencies have used for price review in ESPC projects and the lessons learned.

- Document the options and the "best practices" in implementing those options.

- Develop consensus across the various federal ESPC IDIQ programs on how price review will be performed by all going forward.

\section{$\underline{\text { Final Deliverables }}$}

Report on federal best practices for price review in ESPC projects, with recommended procedures to ensure fair and reasonable pricing. 


\title{
APPENDIX B - \\ Membership of Price ReAsonableness Working GROUP
}

\author{
John Shonder, Chair, Oak Ridge National Laboratory \\ Kelly Dowd, Defense Energy Support Center \\ John Lloyd, U.S. Navy \\ Pat Mumme, U.S. Air Force \\ Linda Sisk, U.S. Air Force \\ Tatiana Strajnic, U.S. DOE/FEMP \\ David Williams, U.S. Army \\ Carl Zeigler, U.S. Marines
}




\section{APPENDIX C - FAR 15.404-1}

\subsection{Proposal analysis}

\subsection{4-1 Proposal analysis techniques}

(a) General. The objective of proposal analysis is to ensure that the final agreed-to price is fair and reasonable.

(1) The contracting officer is responsible for evaluating the reasonableness of the offered prices. The analytical techniques and procedures described in this subsection may be used, singly or in combination with others, to ensure that the final price is fair and reasonable. The complexity and circumstances of each acquisition should determine the level of detail of the analysis required.

(2) Price analysis shall be used when cost or pricing data are not required (see paragraph (b) of this subsection and 15.404-3).

(3) Cost analysis shall be used to evaluate the reasonableness of individual cost elements when cost or pricing data are required. Price analysis should be used to verify that the overall price offered is fair and reasonable.

(4) Cost analysis may also be used to evaluate information other than cost or pricing data to determine cost reasonableness or cost realism.

(5) The contracting officer may request the advice and assistance of other experts to ensure that an appropriate analysis is performed.

(6) Recommendations or conclusions regarding the Government's review or analysis of an offeror's or contractor's proposal shall not be disclosed to the offeror or contractor without the concurrence of the contracting officer. Any discrepancy or mistake of fact (such as duplications, omissions, and errors in computation) contained in the cost or pricing data or information other than cost or pricing data submitted in support of a proposal shall be brought to the contracting officer's attention for appropriate action.

(7) The Air Force Institute of Technology (AFIT) and the Federal Acquisition Institute (FAI) jointly prepared a five-volume set of Contract Pricing Reference Guides to guide pricing and negotiation personnel. The five guides are: I Price Analysis, II Quantitative Techniques for Contract Pricing, III Cost Analysis, IV Advanced Issues in Contract Pricing, and V Federal Contract Negotiation Techniques. These references provide detailed discussion and examples applying pricing policies to pricing problems. They are to be used for instruction and professional guidance. However, they are not directive and should be considered informational only. They are available via the internet at http://www.acq.osd.mil/dp/cpf. 
(b) Price analysis.

(1) Price analysis is the process of examining and evaluating a proposed price without evaluating its separate cost elements and proposed profit.

(2) The Government may use various price analysis techniques and procedures to ensure a fair and reasonable price. Examples of such techniques include, but are not limited to, the following:

(i) Comparison of proposed prices received in response to the solicitation. Normally, adequate price competition establishes price reasonableness (see $15.403-1(\mathrm{c})(1))$.

(ii) Comparison of previously proposed prices and previous Government and commercial contract prices with current proposed prices for the same or similar items, if both the validity of the comparison and the reasonableness of the previous price(s) can be established.

(iii) Use of parametric estimating methods/application of rough yardsticks (such as dollars per pound or per horsepower, or other units) to highlight significant inconsistencies that warrant additional pricing inquiry.

(iv) Comparison with competitive published price lists, published market prices of commodities, similar indexes, and discount or rebate arrangements.

(v) Comparison of proposed prices with independent Government cost estimates.

(vi) Comparison of proposed prices with prices obtained through market research for the same or similar items.

(vii) Analysis of pricing information provided by the offeror.

(3) The first two techniques at 15.404-1(b)(2) are the preferred techniques. However, if the contracting officer determines that information on competitive proposed prices or previous contract prices is not available or is insufficient to determine that the price is fair and reasonable, the contracting officer may use any of the remaining techniques as appropriate to the circumstances applicable to the acquisition.

(4) Value analysis can give insight into the relative worth of a product and the Government may use it in conjunction with the price analysis techniques listed in paragraph (b)(2) of this section.

(c) Cost analysis.

(1) Cost analysis is the review and evaluation of the separate cost elements and profit in an offeror's or contractor's proposal (including cost or pricing data or information other than cost or pricing data), and the application of judgment to determine how well the proposed costs represent what the cost of the contract should be, assuming reasonable economy and efficiency. 
(2) The Government may use various cost analysis techniques and procedures to ensure a fair and reasonable price, given the circumstances of the acquisition. Such techniques and procedures include the following:

(i) Verification of cost or pricing data and evaluation of cost elements, including-

(A) The necessity for, and reasonableness of, proposed costs, including allowances for contingencies;

(B) Projection of the offeror's cost trends, on the basis of current and historical cost or pricing data;

(C) Reasonableness of estimates generated by appropriately calibrated and validated parametric models or cost-estimating relationships; and

(D) The application of audited or negotiated indirect cost rates, labor rates, and cost of money or other factors.

(ii) Evaluating the effect of the offeror's current practices on future costs. In conducting this evaluation, the contracting officer shall ensure that the effects of inefficient or uneconomical past practices are not projected into the future. In pricing production of recently developed complex equipment, the contracting officer should perform a trend analysis of basic labor and materials, even in periods of relative price stability.

(iii) Comparison of costs proposed by the offeror for individual cost elements with-

(A) Actual costs previously incurred by the same offeror;

(B) Previous cost estimates from the offeror or from other offerors for the same or similar items;

(C) Other cost estimates received in response to the Government's request;

(D) Independent Government cost estimates by technical personnel; and

(E) Forecasts of planned expenditures.

(iv) Verification that the offeror's cost submissions are in accordance with the contract cost principles and procedures in Part 31 and, when applicable, the requirements and procedures in 48 CFR Chapter 99 (Appendix to the FAR looseleaf edition), Cost Accounting Standards.

(v) Review to determine whether any cost or pricing data necessary to make the contractor's proposal accurate, complete, and current have not been either submitted or identified in writing by the contractor. If there are such data, the contracting officer shall attempt to obtain them and negotiate, using them or making satisfactory allowance for the incomplete data.

(vi) Analysis of the results of any make-or-buy program reviews, in evaluating subcontract costs (see 15.407-2). 
(d) Cost realism analysis.

(1) Cost realism analysis is the process of independently reviewing and evaluating specific elements of each offeror's proposed cost estimate to determine whether the estimated proposed cost elements are realistic for the work to be performed; reflect a clear understanding of the requirements; and are consistent with the unique methods of performance and materials described in the offeror's technical proposal.

(2) Cost realism analyses shall be performed on cost-reimbursement contracts to determine the probable cost of performance for each offeror.

(i) The probable cost may differ from the proposed cost and should reflect the Government's best estimate of the cost of any contract that is most likely to result from the offeror's proposal. The probable cost shall be used for purposes of evaluation to determine the best value.

(ii) The probable cost is determined by adjusting each offeror's proposed cost, and fee when appropriate, to reflect any additions or reductions in cost elements to realistic levels based on the results of the cost realism analysis.

(3) Cost realism analyses may also be used on competitive fixed-price incentive contracts or, in exceptional cases, on other competitive fixed-price-type contracts when new requirements may not be fully understood by competing offerors, there are quality concerns, or past experience indicates that contractors' proposed costs have resulted in quality or service shortfalls. Results of the analysis may be used in performance risk assessments and responsibility determinations. However, proposals shall be evaluated using the criteria in the solicitation, and the offered prices shall not be adjusted as a result of the analysis.

(e) Technical analysis.

(1) The contracting officer may request that personnel having specialized knowledge, skills, experience, or capability in engineering, science, or management perform a technical analysis of the proposed types and quantities of materials, labor, processes, special tooling, facilities, the reasonableness of scrap and spoilage, and other associated factors set forth in the proposal(s) in order to determine the need for and reasonableness of the proposed resources, assuming reasonable economy and efficiency.

(2) At a minimum, the technical analysis should examine the types and quantities of material proposed and the need for the types and quantities of labor hours and the labor mix. Any other data that may be pertinent to an assessment of the offeror's ability to accomplish the technical requirements or to the cost or price analysis of the service or product being proposed should also be included in the analysis.

(f) Unit prices.

(1) Except when pricing an item on the basis of adequate price competition or catalog or market price, unit prices shall reflect the intrinsic value of an item or service and shall be in proportion to an item's base cost (e.g., manufacturing or acquisition costs). Any method of distributing costs to line items that distorts the unit prices shall not be 
used. For example, distributing costs equally among line items is not acceptable except when there is little or no variation in base cost.

(2) Except for the acquisition of commercial items, contracting officers shall require that offerors identify in their proposals those items of supply that they will not manufacture or to which they will not contribute significant value, unless adequate price competition is expected (10 U.S.C. 2304 and 41 U.S.C. 254(d)(5)(A)(i)). Such information shall be used to determine whether the intrinsic value of an item has been distorted through application of overhead and whether such items should be considered for breakout. The contracting officer may require such information in all other negotiated contracts when appropriate.

(g) Unbalanced pricing.

(1) Unbalanced pricing may increase performance risk and could result in payment of unreasonably high prices. Unbalanced pricing exists when, despite an acceptable total evaluated price, the price of one or more contract line items is significantly over or understated as indicated by the application of cost or price analysis techniques. The greatest risks associated with unbalanced pricing occur when-

(i) Startup work, mobilization, first articles, or first article testing are separate line items;

(ii) Base quantities and option quantities are separate line items; or

(iii) The evaluated price is the aggregate of estimated quantities to be ordered under separate line items of an indefinite-delivery contract.

(2) All offers with separately priced line items or subline items shall be analyzed to determine if the prices are unbalanced. If cost or price analysis techniques indicate that an offer is unbalanced, the contracting officer shall-

(i) Consider the risks to the Government associated with the unbalanced pricing in determining the competitive range and in making the source selection decision; and

(ii) Consider whether award of the contract will result in paying unreasonably high prices for contract performance.

(3) An offer may be rejected if the contracting officer determines that the lack of balance poses an unacceptable risk to the Government. 


\section{APPENDIX D - BENCHMARKS: A More Rigorous Approach to Price Analysis}

Price benchmarks are cost estimating relationships that consider the price of a good or service to be a function of one or more dependent variables related to the size, level of effort, or some other measurable characteristic of the good or service in question. An example would be the cost of constructing office space, expressed in dollars per square foot. While such a benchmark is not accurate enough for a contractor to make a bid based on it, it would be of use to a potential building owner, to determine whether a bid was comparable to the price of other commercial office space. In ESPC, price benchmarks are useful in reviewing price proposals, to eliminate from scrutiny prices that are in the expected range and focus attention on other prices.

A simple method of developing a price benchmark is to assume a linear relationship between cost and some measure of the item's size. For example, for a chiller replacement project, the variable would likely be total chiller capacity, and one might assume a relationship of the form

$$
C=a+b x
$$

where $C$ is total cost, $x$ is chiller capacity, $b$ is the cost per unit capacity, and $a$ is a constant.

As a simple example, consider Table D.1, which provides information on three (fictitious) chiller projects. The first four columns contain the location of the project, the date the equipment was installed, the total capacity replaced, and the total contract cost. We will assume that the same types of chillers were installed in each case, and the scope of each project is roughly the same, involving only the replacement of one or more chillers, and associated auxiliary equipment.

Table D.1. Chiller replacement projects

\begin{tabular}{lcrrrl}
\hline Location & Date & $\begin{array}{l}\text { Capacity } \\
\text { (tons) }\end{array}$ & \multicolumn{1}{c}{ Cost } & \multicolumn{1}{c}{ CCl } & $\begin{array}{l}\text { Adjusted } \\
\text { price }\end{array}$ \\
\hline $\begin{array}{l}\text { Atlanta, GA } \\
\text { Los Angeles, }\end{array}$ & $9 / 30 / 99$ & 1950 & $\$ 1,271,078$ & 102.90 & $\$ 1,854,118$ \\
CA & & & & & \\
Detroit, MI & $1 / 23 / 01$ & 1125 & $\$ 724,032$ & 132.40 & $\$ 820,825$ \\
\hline
\end{tabular}

In order to compare the prices, we must correct for general price inflation and differences in pricing that are due to the local economy. One way of doing this is to use Means Construction Cost Index (CCI). Published annually, the CCI contains historical data on construction costs in 316 cities in the United States and Canada. For example, for Atlanta in 1999 the CCI is 102.9. These values are also provided in Table D.1.

Suppose we wish to compare these prices to a proposal received for a 1500-ton chiller replacement ECM in Minneapolis. The current CCI for Minneapolis is 150.1. So, to correct each of the prices in Table 1 to Minneapolis in 2004, we multiply each price by 150.1 and divide by the project's CCI. So, for example, the cost of the Atlanta project is 
multiplied by $150.1 / 102.9$ to approximate what it would cost in Minneapolis in 2004. The last column of Table D.2 contains the adjusted price for each project.

Now that we have adjusted all of the prices to the current date and the location of the ESPC project, we can correlate price to chiller capacity. Linear regression of the data gives

$$
\mathrm{C}=-499,952+1203 x
$$

where $\mathrm{C}$ is cost and $x$ is total chiller capacity. Then based on the three past contracts, a reasonable estimate of the price to replace 1500 tons of chiller capacity in Minneapolis in 2004 is $\$ 1,304,548$.

It is important not to assign any physical significance to the terms of the price benchmark equation. For example, the fact that the constant term is negative does not mean that there is a negative setup cost for each project; nor, in general, does the 1203 represent an accurate cost per ton. The equation simply represents the best fit to the data available.

For some ECMs, pricing data may be available over a wide range of ECM sizes. This could be the case for chiller replacements, since such projects could range from the replacement of a single small chiller, with say 15 tons of capacity, up to large projects involving thousands of tons of capacity. In these cases it is more convenient to assume a cost model of the form:

$$
C=e^{\varepsilon} a x^{b}
$$

where $\mathrm{C}$ is cost, $a$ is cost per unit, and $x$ is the size. The variable $b$ is included to account for changes in cost per unit over different size ranges. If the cost per unit is constant over all sizes, then $b=1$. If cost per unit increases with size, then $\mathrm{b}$ will be greater than 1 . If cost per unit size decreases with size, then $b$ will be less than 1 .

The term $e^{\varepsilon}$ accounts for variations in pricing, which are assumed to be random. Here $e$ is the base of natural logarithms, and $\varepsilon$ is a normally distributed random variable, assumed to have a mean of zero. Now suppose the standard deviation of this random variable is small, on the order of 0.10 . According to standard probability theory, about $95 \%$ of the values of $\varepsilon$ will be within two standard deviations of the mean; in other words, $95 \%$ of the values will lie between -0.20 and 0.20. In Eq. D.3 above the variation in pricing is the exponential of these values, so $95 \%$ of the variations will lie between 0.82 and 1.22 . This means that prices vary by $\pm 20 \%$ from the benchmark, approximately.

Taking the natural logarithm of both sides of Eq. D.3 gives:

$$
\ln C=\ln a+b \ln x+\varepsilon,
$$

which is standard form for a linear equation with random errors. Thus in order to develop a pricing benchmark, we correlate the logarithm of cost with the logarithm of size using standard linear regression techniques. Of course, past pricing must be adjusted as above to account for inflation and differences in pricing in different cities across the country. 
The usefulness and accuracy of pricing benchmarks depends on the quantity of data available to develop them. Even if an ECM can be categorized by a readily identifiable size variable, it may be that prices depend heavily on local conditions encountered at the site. In such cases, the variation in pricing may make it difficult to develop useful benchmarks.

DOE FEMP has developed pricing benchmarks based on measures of size for four of the more popular ECMs: chiller replacements, lighting, variable frequency drives for motors, and geothermal heat pumps. The FEMP ESPC team can make information from these pricing benchmarks available to acquisition teams developing ESPC projects with similar ECMs.

An example of the use of the lighting benchmarks is presented in Figure D.1. The figure, which is on a log-log scale, is based on a database that contains pricing data from 65 lighting ECMs carried out under ESPC plus 10 carried out as part of appropriationsfunded energy conservation programs. All of the ECMs were centered on conversion of office lighting to T-8 fixtures and tubes, and included other subsidiary measures such as installation of occupancy sensors, fixture delamping, installation of tandem wiring, and conversion to compact fluorescent lighting

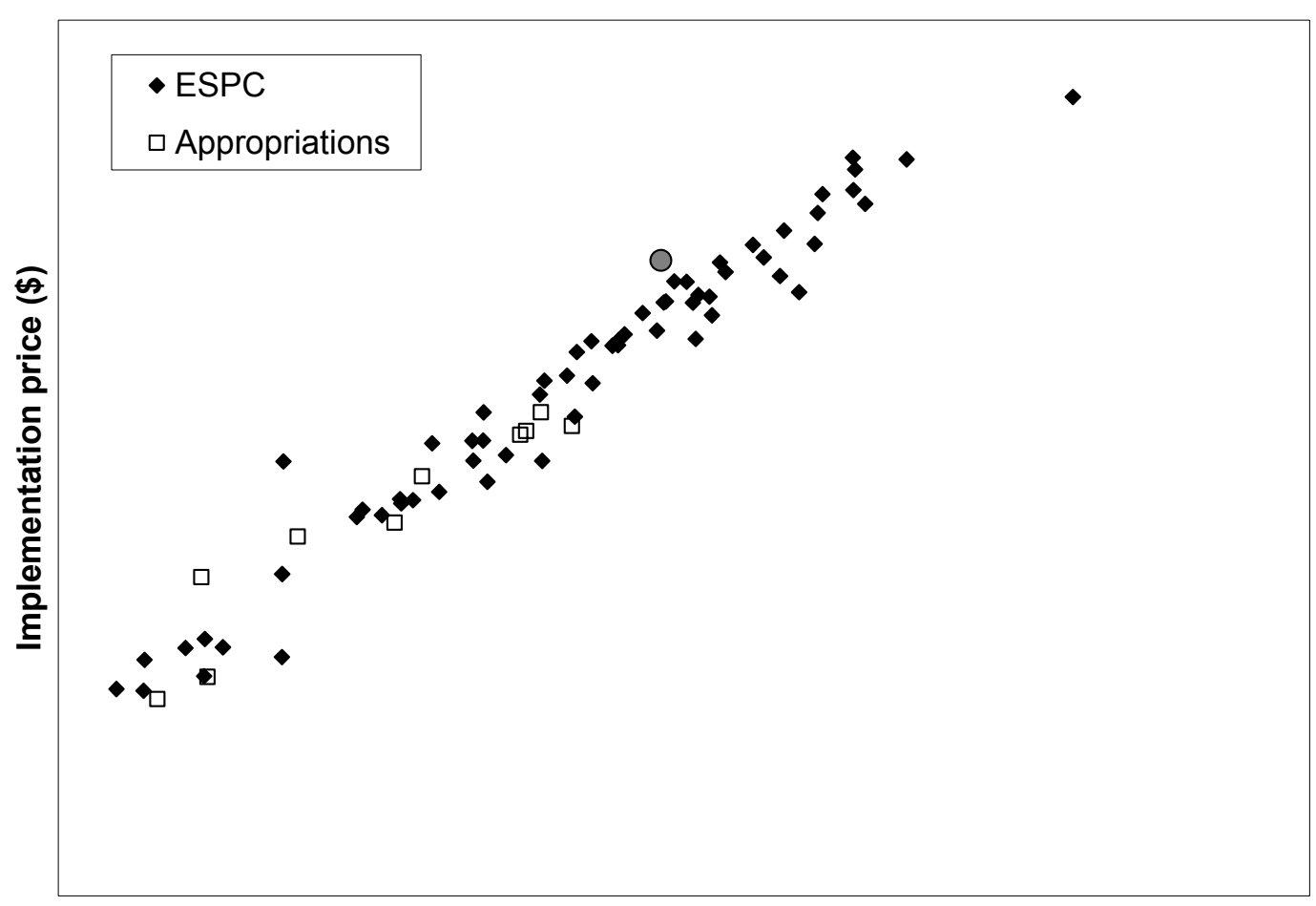

Annual energy savings (kWh)

Figure D.1. An example of the use of lighting benchmarks.

The axes have been removed to protect procurement-sensitive information, but note that there is a well-defined linear relationship between the log of annual savings and log of implementation cost. The gray circle is intended to represent a "new" ECM, whose 
implementation price is being compared with the implementation prices of previous projects. The ECM cost database contains the location of each ECM and the date on which it was installed. To develop Figure D.1, each of the 65 prices were adjusted to one specific city on the same date using Means Construction Cost Index, and the adjusted prices plotted against the annual $\mathrm{kWh}$ savings from the project. If this ECM were being installed in, say, Phoenix, Arizona, the prices of each of the 65 prices would be adjusted according to Phoenix. 